Overview

\title{
Comparative structural and catalytic properties of oxygen-evolving photosystem II preparations*
}

\author{
D.F. GHANOTAKIS, C.M. WAGGONER, N.R. BOWLBY, D.M. \\ DEMETRIOU, G.T. BABCOCK ${ }^{1} \&$ C.F. YOCUM \\ Departments of Biology and Chemistry, The University of Michigan, Ann Arbor, MI \\ 48109-1048 USA; 'Department of Chemistry, Michigan State University, East Lansing, MI \\ 48824, USA
}

Received 2 June 1987; accepted in revised form 4 August 1987

Key words: photosystem II, oxygen evolution, polypeptides, manganese, cytochrome $\mathrm{b}_{559}$

\begin{abstract}
Biochemical techniques now exist to produce the oxygen-evolving complex of photosystem II (PSII) and its associated photochemical redox reactions in various states of purity. These preparations permit one to assess the structural roles of polypeptides in promoting activity by using selective extraction techniques which remove certain polypeptides, to carry out reconstitution studies which re-establish activity, and, in the case of more recently developed, highly purified preparations discussed in this overview, to identify the minimal polypeptide complement necessary for photosynthetic oxygen evolution activity. These comparative investigations also suggest a tentative structure for an oxygen-evolving PSII core complex whose primary constituents are a hydrophobic complex of polypeptides, manganese, calcium and chloride, and the $33 \mathrm{kDa}$ extrinsic polypeptide.
\end{abstract}

Abbreviations: DCBQ-2,6 dichloro-p-benzoquinone, Chl-chlorophyll, LHCP-lightharvesting chlorophyll proteins, PS-photosystem

\section{Introduction}

The use of non-ionic detergents to fractionate thylakoid membranes (Berthold et al. 1981, Kuwabara and Murata 1982b) yields PSII-enriched membrane sheets (Goodman-Dunahay et al. 1984) and has produced new material for the study of the structure and function of the oxygen-evolving reaction. Briefly, these PSII preparations have provided material for a closer examination of the role(s) of extrinsic 33,23 , and $17 \mathrm{kDa}$ proteins (see Ghanotakis and Yocum (1985) Govindjee et al. (1985) and Babcock (1987)

* Presented at the Japan/US Binational Seminar on "Energy Conversion: Photochemical Reaction Centers and Oxygen-Evolving Complexes of Plant Photosynthesis", March 17-21, 1987. See conference report by G. Renger in Photosynthesis Research, in press, 1987 ... Editor. 
for reviews), as well as a vehicle for preparing samples in which spectroscopic studies of PSII-associated electron carriers has been facilitated owing to the absence of PSI. More recently, attempts to use the PSII membranes as the starting material to produce more highly purified PSII preparations have succeeded, opening the way to further investigations on the polypeptide structure of PSII, as well as on the function of these polypeptides in facilitating photo-induced electron transfer from the oxygen-evolving complex to the reducing side of the photo-act. At the same time, these new preparations possess properties markedly different from those associated with the starting material, the more complex preparations of Kuwabara and Murata (1982b) and Berthold et al. (1981). In this overview, we discuss the comparative properties of the various types of PSII preparations available to researchers at the present time.

\section{Polypeptide composition and comparative properties of electron transfer in PSII preparations}

Figure 1 presents a SDS-polyacrylamide gel of three PSII preparations isolated in the author's laboratory. Lane 1 presents the polypeptide composition of PSII membrane sheets, Lane 2 the composition of a reaction center complex, and Lane 3 the composition of a reaction center "core" preparation. The PSII membrane sheet (Lane 1) preparations contain the hydrophobic polypeptides $(47,43,34,32,9$ and $5 \mathrm{kDa})$ of the photochemically active PSII "core" (as originally defined by Satoh (1982) previous to the more recent isolation of the reaction center preparation (Nanba and Satoh 1987) which consists of $34 \mathrm{kDa}$ (D2), $32 \mathrm{kDa}$ (D1, the $\mathrm{Q}_{\mathrm{B}}$ or herbicide binding protein) and cytochrome $b_{559}$ ). Polypeptides in the $29-24 \mathrm{kDa}$ region of the gel are associated with the binding of light-harvesting $\mathrm{Chl}$ a and b (collectively called LHCP). The extrinsic 33,23 , and $17 \mathrm{kDa}$ polypeptides found in this preparation are also noted on the gel; following their discovery by Kuwabara and Murata (1982a) and Åkerlund et al. (1982), these extrinsic species have been studied in both everted thylakoid vesicles and in the PSII membranes sheets to generate an extensive (and still expanding) literature; the current status of research on the extrinsic proteins may be briefly, but by no means comprehensively, summarized as follows:

1. All three proteins are essential for long-term stability and function of the oxygen-evolving reaction in higher plants.

2. The 17 and $23 \mathrm{kDa}$ proteins are necessary to maintain the structural integrity of the oxygen-evolving apparatus in a state where the reaction can function in an environment of low, physiological concentrations of 


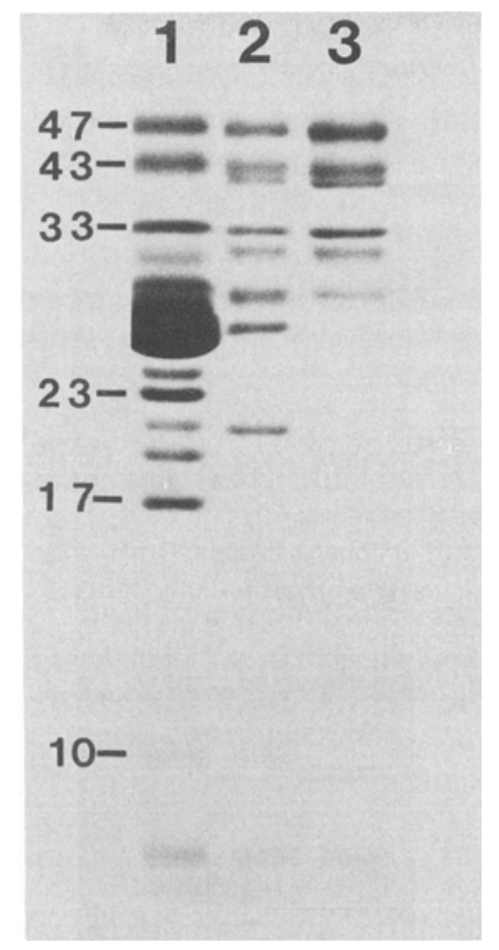

Fig. 1. SDS-polyacrylamide gel electrophoresis patterns of three oxygen-evolving PSII preparations. Lane 1: PSII membrane sheets; Lane 2: reaction center complex; Lane 3: oxygen-evolving reaction center core.

calcium and chloride; in addition the $23 \mathrm{kDa}$ protein, presumably in concert with the $33 \mathrm{kDa}$ species, is necessary to form a shield around the functional manganese cluster which protects it from exogenously added reductants (Waggoner and Yocum 1987).

3. The $33 \mathrm{kDa}$ protein is essential in maintaining the native catalytic activity of the oxygen-evolving reaction. Although the $33 \mathrm{kDa}$ protein can be removed from membrane sheets with full retention of functional manganese, these extracted systems do not retain the control rates of oxygen evolution activity. Recent thermoluminescence work in the laboratory of Inoue (1987) on samples from which the $33 \mathrm{kDa}$ protein has been removed provides evidence that the $33 \mathrm{kDa}$ protein may also have an effect on reactions at the reducing side of PSII.

The ability to utilize elevated concentrations of calcium and chloride to supplant in part the function of the 23 and $17 \mathrm{kDa}$ polypeptides has permitted the application of treatments for the further purification of PSII, treatments which (at least at present) lead to the removal of the 23 and 
$17 \mathrm{kDa}$ proteins along with other polypeptides associated with membrane sheets. This approach is exemplified by the work of Ikeuchi et al. (1985), who combined octylglucoside treatment with sucrose density gradient centrifugation of dissociated PSII membranes to produce a more highly refined PSII preparation. These results were followed by a report from Ghanotakis and Yocum (1986), who employed high concentrations of sodium chloride along with octylglucoside and differential centrifugation to isolate material (whose polypeptide composition is shown in Lane 2 of Fig. 1) which is similar, but not identical to the preparation of Ikeuchi et al. (1985). A major structural feature of such preparations is evident from their polypeptide composition, which shows that the major polypeptides of the light-harvesting apparatus have been removed by the purification procedures. This observation, based on gel electrophoresis, correlates with an approximate 4 to 5 -fold enrichment in reaction centers on a chlorophyll basis, as summarized in Table 1. A principal difference between the two more highly purified reaction center complex preparations reported in the literature to date resides in the absence (in the Ikeuchi et al. (1985) preparation) of a polypeptide with an apparent molecular mass of $22 \mathrm{kDa}$. There are also differences in electron transfer activity on the reducing side of the two preparations (Table 2) which are reflected in a preference for ferricyanide as the acceptor in a DCMU-insensitive reaction when the $22 \mathrm{kDa}$ protein has been removed. The Ikeuchi et al. preparation of the complex also requires digitonin $(0.1 \%)$ in the assay reaction mixture to produce optimal rates of oxygen evolution. With regard to oxidizing side function, the two preparations appear quite similar, both in terms of rates of oxygen evolution as well as in terms of a requirement for elevated concentrations of calcium and chloride for optimal rates of oxygen evolution activity (owing to the absence of the 17 and $23 \mathrm{kDa}$ polypeptides). A characterization of the calcium and chloride responses of the Ikeuchi et al. preparation has been reported by Ikeuchi and Inoue (1986).

Using the more highly refined preparations, Ghanotakis et al. (1987a, $1987 \mathrm{~b}$ ) have removed proteins of 28,22 , and $10 \mathrm{kDa}$ from the oxygen-evolv-

Table 1. Oxygen-evolving preparations: enrichment of PSII components and activity

\begin{tabular}{llll}
\hline & Preparation & & \\
\cline { 2 - 4 } & Berthold et al. & Ikeuchi et al. & Ghanotakis/Yocum \\
\hline $\mathrm{Mn} / \mathrm{Chl}$ & $4 / 250$ & $4 / 68$ & $4 / 68$ \\
$\mathrm{Z}^{+} / \mathrm{Chl}$ & $1 / 260$ & n.d. & $1 / 73$ \\
$\mathrm{~V}_{\mathrm{O} 2}^{\mathrm{a}}$ & $550-700^{\mathrm{b}}$ & $850-1070^{\mathrm{c}}$ & $940^{\mathrm{b}}$ \\
\hline
\end{tabular}

a expressed as $\mu$ moles $\mathrm{O}_{2} / \mathrm{hr} / \mathrm{mg} \mathrm{Chl}$

${ }^{b}$ with DCBQ as the electron acceptor

c with ferricyanide as the acceptor in the presence of $0.1 \%$ digitonin 
ing reaction center complex by FPLC gel filtration to produce a 7-polypeptide reaction center core PSII preparation (Lane 3 of Fig. 1) which is capable of high rates of activity; ferricyanide now acts in this preparation as the preferred, but largely DCMU-insensitive acceptor. A similar type of preparation possessing substantially lower rates of oxygen evolution, isolated by the use of ion-exchange purification on DEAE Toyopearl, has been reported by Yamada et al. (1987), and Ikeuchi and Inoue (1986) have further purified their preparation. The reader should note that the purified oxygen-evolving "core" preparations posses reducing side electron transfer properties which are similar, if not identical to, those exhibited by the original reaction center preparation described by Ikeuchi et al. (1985), namely the predominance of DCMU-insensitive, ferricyanide-catalyzed activity as shown in Table 2, rather than DCMU-sensitive activity catalyzed by DCBQ.

Taken together, the results so far available from research on the oxygenevolving reaction center "cores" implicate the hydrophobic polypeptides (47, 43, 34 (D2), 32 (D1), 9 and $5 \mathrm{kDa}$ ) which form the photochemically active core of PSII, along with manganese, calcium, chloride and the extrinsic $33 \mathrm{kDa}$ protein as the minimal structural-cofactor unit which is capable of oxygen evolution activity. One of the common properties of these oxygenevolving "core" preparations is the absence of an extrinsic $10 \mathrm{kDa}$ protein, which was earlier proposed to be an essential component of PSII preparations capable of water oxidation (Ljungberg et al. 1984a). The relationship of polypeptides found in PSII membrane sheets to activity in the highly purified preparations described here remain to be elucidated. Other questions are raised by the properties of the reaction center complex and "core" preparations which have not yet been addressed, and a brief overview of the comparative properties of the various PSII preparations raises the following issues:

Table 2. Acceptor function in PSII reaction center complexes

$\mathrm{O}_{2}$ evolution activity ${ }^{\mathrm{a}}$ assayed in preparations according to:

Ikeuchi et al. Ghanotakis/Yocum

Acceptor/Inhibitor

Additions

$\begin{array}{lll}\text { DCBQ } & 893 & 940\end{array}$

$\mathrm{DCBQ}+\mathrm{DCMU} \quad 765 \quad 530$

$\mathrm{Fe}(\mathrm{CN})_{6}^{3-}-1481 \quad 230$

$\mathrm{Fe}(\mathrm{CN})_{6}^{3-}+\mathrm{DCMU} \quad 1369 \quad 190$

a expressed as $\mu$ moles $\mathrm{O}_{2} / \mathrm{hr} / \mathrm{mgChl}$ 
1. Are there new functional lesions created on the oxidizing side of PSII by the treatments required to produce more highly purified material, which are reflected in the loss of polypeptides found in membrane sheets? The rates of oxygen evolution activity reported for refined preparations is consistent with an enrichment in reaction centers on a chlorophyll basis, but the activities so far reported are lower than expected for activity in a system where a 4- to 5-fold purification has been obtained. Is this due to damaged centers in which manganese remains esr silent? Is it possible that removal of the LHCP complex has caused drastic alterations in quantum efficiency? In utilizing further detergent treatments, have important lipid constituents been stripped away from reaction center polypeptides? Further investigations are obviously necessary to clarify these questions.

2. To what extent can the structural properties of PSII membrane sheets be reconstituted in the more purified material? We (Merritt et al. 1987) have presented preliminary evidence for rebinding of 17 and $23 \mathrm{kDa}$ proteins to the preparation lacking the LHCP complex, and it will be useful to know whether similar reconstitutions are possible with the oxygenevolving reaction center core. At the same time, future research on isolation of complexes should determine whether purification procedures can be developed which permit the removal of LHCP complex without extraction of the extrinsic 23 and $17 \mathrm{kDa}$ species.

3. What is the origin of the changes observed in reducing side function after removal of the $22 \mathrm{kDa}$ protein? Is the appearance of DCMU-insensitive ferricyanide reduction a fortuitous consequence of the purification procedure itself? Is it possible that the $22 \mathrm{kDa}$ protein is responsible for binding of extrinsic proteins, as implied by the data of Ljungberg et al. (1984b) and in addition responsible for regulation of electron transfer on the reducing side of PSII? Comparative investigations by several groups (Ghanotakis et al. 1987b, Henrysson et al. 1987, Ikeuchi and Inoue 1986, Yamada et al. 1987) correlate the loss of quinone-catalyzed electron transfer activity with the extraction of the $22 \mathrm{kDa}$ protein and the appearance of DCMU-insensitive ferricyanide reduction activity. It will be interesting to see whether further research can establish the $22 \mathrm{kDa}$ species as the PSII equivalent of the " $\mathrm{H}$ " subunit in photosynthetic bacteria.

4. Are small polypeptides required for PSII activity? Henrysson et al. (1987) have presented evidence for the presence of a number of tenaciously bound small polypeptides in a number of PSII preparations, including oxygen-evolving reaction center complexes. Of these species, 
three $(4,5,5.5 \mathrm{kDa})$ were present in all PSII preparations surveyed by the authors. In light of this finding, further investigations on low-molecular weight polypeptides are necessary to establish their role(s) in oxygen evolution and/or photochemical electron transfer reactions.

\section{Conclusions}

Table 3 summarizes the properties of oxygen-evolving PSII preparations which are now available for use in biochemical and biophysical research on primary electron transfer and the oxygen-evolving reaction. As is apparent from the Table, new, more purified material offers the immediate advantage to the investigator of an enrichment in reaction center components on a chlorophyll basis. The disadvantages, at the present time is that these preparations represent structurally as well as functionally altered forms of the better-characterized membrane sheet preparations. Although high concentrations of calcium and chloride will activate the oxygen-evolving complex in the more purified preparations, one must at the same time realize that changes have also occurred to activity on the reducing side of the photoact. It is likely that experiments now in progress in several laboratories will better define the activities of PSII preparations containing fewer polypeptides than the PSII membrane sheets used as starting material, and that with this knowledge, these new preparations will prove to be useful adjuncts to the membrane sheet preparations, which are now widely used for PSII research.

Table 3. Comparative properties of oxygen-evolving PSII preparations

\begin{tabular}{llll}
\hline & Membrane sheets & Complex & "Core" \\
\hline $\mathrm{V}_{\mathrm{O} 2}^{+}$ & $500-700$ & $>1000$ & $>1000$ \\
$\mathrm{Ca}^{2+} / \mathrm{Cl}$ - requirement & Low & $\mathrm{High}$ & High \\
$\mathrm{TRAP} / \mathrm{CHL}$ ratio & $1 / 250$ & $1 / 68$ & $1 / 40^{*}$ \\
Acceptor preference & $\mathrm{DCBQ}$ & $\mathrm{DCBQ}{ }^{* *}$ & $\mathrm{Fe}(\mathrm{CN})_{6}^{3-}$ \\
& & $\mathrm{Fe}(\mathrm{CN})_{6}^{3-* * *}$ & \\
ESR multiline signal & Present & Present & Present**** \\
Polypeptides released by & PSI & LHCP & $28 \mathrm{kDa}(\mathrm{CP} 29 ?)$ \\
purification procedures & $\mathrm{b}_{6} / \mathrm{f}$ & $23 \mathrm{kDa}$ & $22 \mathrm{kDa}$ \\
& $\mathrm{CF}_{1} / \mathrm{CF}_{0}$ & $17 \mathrm{kDa}^{*}$ & $10 \mathrm{kDa}$ \\
& & $22 \mathrm{kDa}$ & \\
\hline
\end{tabular}

\footnotetext{
$+\quad$ expressed in $\mu$ moles $\mathrm{O}_{2} / \mathrm{hr} / \mathrm{mg} \mathrm{Chl}$

* based on Mn content; see Ikeuchi and Inoue (1986)

** for the reaction center complex prepared as in Ghanotakis and Yocum (1986)

*** for the reaction center complex prepared as in Ikeuchi et al. (1985)

**** reported in the preparation described in Yamada et al. (1987)
} 
Certainly, the availability of oxygen-evolving PSII preparations in which the number of polypeptides can be varied either by purification procedures, or by the use of extraction and reconstitution methods, provides an opportunity to explore in detail the roles of these polypeptides as either structural or catalytic components in the oxygen-evolving reacton of PSII.

\section{Acknowledgements}

This overview is based on a presentation made by CFY at a Japan/US Binational Seminar on Solar Energy Conversion: Photochemical Reaction Centers and Oxygen-Evolving Complexes of Plant Photosynthesis held at the National Institute for Basic Biology, Okazaki, Japan. The Seminar was organized by Profs Norio Murata and George Cheniae with support from the US National Science Foundation and by the Ministry of Education, Science and Culture of the Government of Japan. The research programs of CFY and GTB are supported by the National Science Foundation (Metabolic Biology Program) (CFY), the Competitive Research Grants Office of the Science and Education Administration of USDA (CFY and GTB), and the National Institutes of Health (GTB). The impetus for this overview is based in substantial part on the discussions held at Okazaki.

\section{References}

Åkerlund H-E, Jansson C and Andersson B (1982) Reconstitution of photosynthetic water splitting in inside-out thylakoid vesicles and identification of a participating polypeptide. Biochim Biophys Acta 681: 1-10

Babcock GT (1987) The photosynthetic oxygen-evolving process. In: Amesz J (ed.) New Comprehensive Biochemistry: Photosynthesis, (in press). Amsterdam: Elsevier

Berthold DA, Babcock GT and Yocum CF (1981) A highly-resolved, oxygen-evolving photosystem II preparation from spinach thylakoid membranes: EPR and electron transport activities. FEBS Lett 134: 231-234

Ghanotakis DF and Yocum CF (1985) Polypeptides of photosystem II and their role in oxygen evolution. Photosynth Res 7: 97-114

Ghanotakis DF and Yocum CF (1986) Purification and properties of an oxygen-evolving reaction center complex from photosystem II membranes: A simple procedure utilizing a non-ionic detergent and elevated ionic strength. FEBS Lett 197: 244-248

Ghanotakis DF, Demetriou DM and Yocum CF (1987a) Purification of an oxygen-evolving photosystem II reaction center core preparation. In: Biggins J (ed.) Progress in Photosynthesis Research, Vol. 1, pp. 681-684. Dordrecht: Martinus Nijhoff Publishers

Ghanotakis DF, Demetriou DM and Yocum CF (1987b) Isolation and characterization of an oxygen-evolving photosystem II reaction center core preparation and a $28 \mathrm{kDa} C \mathrm{Chl}$-a-binding protein. Biochim Biophys Acta 891: 15-21 
Goodman-Dunahay T, Staehelin A, Seibert M, Ogilivie PD and Berg S (1984) Structural, biochemical, and biophysical characterization of four oxygen-evolving photosystem II preparations. Biochim Biophys Acta 764: 179-193

Govindjee, Kambara T and Coleman W (1985) The electron donor side of photosystem II: The oxygen-evolving complex. Photochem Photobiol 42: 187-210

Henrysson T, Ljungberg U, Franzen L-G, Andersson B and Åkerlund H-E (1987) Low molecular weight polypeptides in photosystem II and protein dependent acceptor requirement for photosystem II. In: Biggins J (ed.) Progress in Photosynthesis Research, Vol. 2, pp. 125-128. Dordrecht: Martinus Nijhoff Publishers

Ikeuchi $\mathrm{M}$ and Inoue $\mathrm{Y}$ (1986) Characterization of $\mathrm{O}_{2}$ evolution by a wheat photosystem II reaction center complex isolated by a simplified method: Disjunction of secondary acceptor quinone and enhanced $\mathrm{Ca}^{2+}$ demand. Arch Biochem Biophys 247: 97-107

Ikeuchi M, Yuasa $\mathrm{M}$ and Inoue $\mathrm{Y}$ (1985) Simple and discrete isolation of an $\mathrm{O}_{2}$-evolving PSII reaction center complex retaining $\mathrm{Mn}$ and the extrinsic $33 \mathrm{kDa}$ protein. FEBS Lett 185 : 316-322

Inoue $\mathrm{Y}$ (1987) Thermoluminescence studies of the abnormal S-states formed in $\mathrm{Cl}^{-}$-depleted PSII. In: Biggins J (ed.) Progress in Photosynthesis Research, Vol 1, pp. 637-648. Dordrecht: Martinus Nijhoff Publishers

Kuwabara T and Murata N (1982a) An improved purification method and a further characterization of the 33-kilodalton protein of spinach chloroplasts. Biochim Biophys Acta 680: 210-215

Kuwabara T and Murata N (1982b) Inactivation of photosynthetic oxygen evolution and concomitant release of three polypeptides in the photosystem II particles of spinach chloroplasts. Plant Cell Physiol 23: 533-539

Ljungberg U, Åkerlund H-E and Andersson B (1984a) The release of a 10-kDa polypeptide from everted photosystem II thylakoid membranes by alkaline Tris. FEBS Lett 175: $255-258$

Ljungberg U, Åkerlund H-E, Larsson C and Andersson B (1984b) Identification of polypeptides associated with the 23 and $33 \mathrm{kDa}$ proteins of photosynthetic oxygen evolution. Biochim Biophys Acta 767: 145-152

Merritt S, Ernfors P, Ghanotakis DF and Yocum CF (1987) Binding of the 17 and $23 \mathrm{kDa}$ water-soluble polypeptides to a highly-resolved PSII reaction center complex. In: Biggins $\mathbf{J}$ (ed.) Progress in Photosynthesis Research, Vol. 1, pp. 681-694. Dordrecht: Martinus Nijhoff Publishers

Nanba O and Satoh K (1987) Isolation of a photosystem II reaction center consisting of D-1 and D-2 polypeptides and cytochrome $b_{559}$. Proc Natl Acad Sci USA 84: 109-112

Satoh K (1982) Fractionation of thylakoid-bound chlorophyll-protein complexes by isoelectric focussing. In: Edelman M, Hallick RB and Chua N-H (eds) Methods in Chloroplast Molecular Biology, pp. 845 856. Amsterdam: Elsevier Biomedical

Waggoner CM and Yocum CF (1987) Selective depletion of water-soluble polypeptides associated with photosystem II. In: Biggins J (ed.) Progress in Photosynthesis Research, Vol. 1, pp. 685-688. Dordrecht: Martinus Nijhoff Publishers

Yamada Y, Tang X-S, Itoh S and Satoh K (1987) Purification and properties of an oxygenevolving photosystem II reaction-center complex from spinach. Biochim Biophys Acta 891: 129-137 